\title{
Findommes, Cybermediated Sex Work, and Rinsing
}

\author{
Rosey McCracken ${ }^{1} \cdot$ Belinda Brooks-Gordon ${ }^{1}$ (I)
}

Accepted: 14 June 2021 / Published online: 4 September 2021

(c) The Author(s), under exclusive licence to Springer Science+Business Media, LLC, part of Springer Nature 2021

\begin{abstract}
Introduction Financial domination involves the payment of cash or gifts from a wish list by a money slave to a money mistress, financial dominatrix, or findomme. Boundaries for findommes working through webcam and video-call services may be more fluid than via text-based modes since the domme engages in more visible displays, and modification of language, voice, and feelings to fulfil the fantasy for a client. We explore the nature of findomme work and its relationship to BDSM to understand how the interaction progresses and how the boundaries, of reasonable and permissible behaviour which affect both incoming and outgoing interactions between people, are maintained.

Methods The study was in two stages. The first stage was a survey of online findommes $(n=56)$ in UK and the USA. For the second stage, we explored the experience of findommes $(n=195)$ on money-slavery websites and social media feeds using netnography as an observation method with cisgender male, female, and transgender participants.

Results Our analysis reveals how findomme interaction progresses from text-based interaction to virtual face-to-face and voice communication. We show financial domination to be on a continuum from being a lifestyle choice in the BDSM community that reaps financial benefits to a purely economic and legitimate form of commercial labour. Although financial domination clearly elicits sexual arousal for clients, the relationship can also be exclusively psychological and focus on the relinquishing of control to a money mistress for a prescribed period.

Conclusion The findings also show how personal boundaries are negotiated and enhance understanding of how the microculture of findomming interacts with other microcultures. By demystifying the process of financial domination, we clarify its relationship with other microcultures and add to the growing body of literature that destigmatizes consensual erotic labour. Implications These findings show how online support, in a decriminalised environment, enabled new and 'instadommes' to set and maintain healthy boundaries for enhanced physical and psychological well-being, and the research provides valuable insight into sex work that is safely carried out in online spaces by a large number of participants so adding to the growing body of work on decriminalization.
\end{abstract}

Keywords BDSM $\cdot$ Cybersex $\cdot$ Dominatrix $\cdot$ Financial $\cdot$ Domination $\cdot$ Kink $\cdot$ Sex work

\section{Introduction}

The range of digital platform communications has changed over the past decade due to the expansion and standardization of platforms. Users communicate rapidly and with relative ease across geographical divides. Digital platforms are now an integral part of our lives including work, social, and sexual interactions. In addition to opportunities for exploring sexuality, the potential of digital platforms for mass distribution enables various types of online sex work or 'cybersex' such

Belinda Brooks-Gordon

b.brooks-gordon@bbk.ac.uk

1 Birkbeck, University of London, London, UK as webcam sex shows. Sex work of this nature may involve real-time (synchronous) or text-based (asynchronous) communication between workers and clients - who may request a performer to carry out specific tasks (Weiss, 2018). In such relationships, the digital platform offers opportunities for selfpresentation and manufacturing a desirable social and sexual identity (Zhao et al., 2008). On digital platforms, people report higher numbers of sexual partners, a higher level of 'outness', friends' support, and stronger connections to 'alternative' communities seeking sex online (Shilo \& Mor, 2015).

For clients wishing to engage in sexual services, digital platforms (DPs) offer the triple A factor in terms of them being affordable (competitive prices and opportunities to gain 'free' sexual pleasure), anonymous, (people perceive interactions are anonymous), and accessible in that there 
is an abundance of sites to fulfil one's needs (Cooper et al., 2000). Sex work via such platforms may reduce some of the physical risks of full-contact work for sex workers, reduce third-party management, and limit intervention from the criminal justice system and enable authenticity (Bernstein, 2007; Orchard et al., 2021). By offering specialist services to specific, or more elite clientele, it has been found that workers may also increase their income (Sanders, 2005a).

One such specialist service is financial domination which involves or the payment of cash and gifts from a digitally based wish list by a money slave to a money mistress or 'financial dominatrix' or findomme. Its growth parallels that of social media 'influencer' culture and its monetisation by content creators to subscribers means that the use of sexualised fan sites has also become more mainstream. Sites such as OnlyFans which occupies the space between influencer culture and webcamming claims more than $1 \mathrm{M}$ content creators and 100 million+ registered users with a claim of $\$ 3$ million+ paid annually to creators (https://onlyfans.com/ about). Findommes offer a niche online service of photos or verbal humiliation for customers which is only just beginning to receive mainstream attention (e.g., Hosie, 2021). It is often aligned to BDSM, and there may be no other connection between the 'domme' and their customer, or there may be an ongoing relationship that builds. Findomme work has reportedly flourished during the COVID-19 pandemic as sex workers, dominatrices, and their customers migrated to DPs due to social distancing precautions (Weiss, 2021). Prior to the pandemic, the findings of Campbell et al. (2019) highlighted how legal and policy changes which sought to ban online adult services advertising and sex work-related content within DPs would have direct impact on the safety strategies online sex workers employ and would be detrimental to their safety, so it is within the context of decriminalization, current UK harm reduction strategies (Sanders et al., 2020), Europe (ALDE, 2019), and progressive policy position of some USA election candidates (see Brents et al., 2021) that this study is presented.

\section{Emotional Labour and Financial Domination}

In her classic study, Chapkis (1997) suggests that all forms of erotic labour may place psychological demands upon workers, some of which may be excessive. A range of research studies (Scambler \& Paoli, 2008; Ward \& Day, 2004) focused upon the effects of the suppression or manufacturing of emotions during their work and their effects upon the workers' physical and psychological well-being. Studies of phone-sex workers (Flowers, 1998; Rich \& Guidroz, 2000), for example, suggest that issues of emotional labour and concealed stigma (c.f. Koken, 2012; Koken et al., 2014) were present even where work occurred in an anonymous and disembodied space. Considering the diversity of digital platforms and the opportunities for both 'real-time' and asynchronous interactions, questions regarding emotional labour and the potential for emotional risk are increasingly important considerations for research in light of the opportunities for expansion of webcam services and the wider cybersex industry (Jones, 2020). Hothschild's (1983) concept of emotional labour encompasses the manufacturing, enhancing, or suppressing of emotions to modify or regulate emotional expression and manage emotions according to the display rules of the work. Using 'surface acting', an individual modifies their behaviours to elicit the desired response in another person, whilst remaining aware of the deception. The process of 'deep acting' involves a deeper level of emotion work where the individual attempts to modify actual feelings to match required displays. Surface acting is arguably negatively associated, but deep acting is positively associated, with affective emotional displays during customer interactions (Grandey, 2000; Scott \& Barnes, 2011; Vartabedian, 2017).

Whilst over-identification with a role may be dangerous, as it may preclude the individual from having some respite from the emotional labour being performed, deep acting and role play may offer protection and support to female sex workers in terms of managing emotional risk, separating their work/personal lives, and managing the nature of their interactions (Abel, 2011; Chapkis, 1997; Sanders, 2005a). Emotional labour also encompasses the effort, planning, and control needed to express emotions during interpersonal interactions and considers the regularity, extent, and intensity of interaction, the diversity of emotions utilised and emotional dissonance - a condition that signifies that the emotions articulated are discrepant from the emotions felt (Ashforth \& Humphrey, 1993; Morris \& Feldman, 1996). This adaptation may be of relevance to contact over digital platforms that provide opportunities for frequent, anonymous, but intense interactions.

\section{Sexual Microcultures in Digital Space}

Digital platforms have become populated by disenfranchised subcultures which may have non-mainstream sexual or psychological preferences. They offer the opportunity to locate like-minded others and enhance networking and selfexpression. Some subcultures have a purely online existence and are linked to contacts who have the same sexual preferences. One of the earliest of these included virtual roleplay activities in 'second life' which enabled participants to realise fantasies and possibilities that might otherwise not be possible or sanctioned in the 'real' world, but without risking marginalisation or stigmatisation (Salter, 2011). Sexual subcultures have also been subject to the commercialisation of digital platforms and can enjoy easy and anonymous access to online sex shops that cater to their specific interests (Palanadri \& Green, 2000; Jones, 2020). These include, for 
example, recreational or 'lifestyle' interests in 'fetish' or bondage, domination/sadomasochism (BDSM) (Breslow, et al., 1985; Breslow, 1986; De Neef et al., 2019; Brown et al., 2020; Cascalleira et al., 2021). Digital platforms offer opportunities for strengthening social acceptance, reduced social isolation, and opportunities for making contacts (Orchard et al., 2021).

The subculture of money slavery or financial domination (FD) is one of the activities that proliferated through the rapid growth of DP websites. Financial domination (FD) involves 'rinsing' or the payment of cash, gifts from a computer-based wish list by a money slave to a money mistress or 'financial dominatrix' or findomme. While Morris (2018) described 'rinsing' in incidental sex work in gay male subcultures, the work of findommes is characterised by a strong sense of entitlement; online postings by findommes are identified as offering, in some incidences, a 'service' of verbal humiliation or photos, but reciprocity is in no sense guaranteed.

Academic literature on FD is scarce although some information on its participants and their motives has been gathered using ethnographic methods (Durkin, 2007). Little is known, however, about participant demographics or whether exchanges move beyond text-based interaction to encompass visible and 'real time' (i.e., synchronous) digital platform communications. Findommes' text-based demands for money may reflect an online disinhibition effect due to dissociative anonymity and where a person can separate their online actions from their day-to-day selves and responsibilities by virtue of being anonymous. Suler (2004) suggests that DP work enables the form of 'toxic dis inhibition' that has been shown to characterise findomme postings and which may be due to the ability to draw upon dis-associative imagination and the creation of a persona that is not subject to the rules and demands of the real world. Griffiths (2016) suggests that the world of findommes is tantamount to wallet rape, and that it takes advantage of the addictive nature of the BDSM client/submissive-a suggestion many participants may find offensive. Financial domination is, therefore, a burgeoning area and new ground in which academic research is only beginning to surface (Swallow, 2018).

The absence of direct communication with findomme participants has meant that there is uncertainty, however, as to whether 'money slaves' are content to offer money and goods 'gratis' or whether there is the expectation or demand for some form of erotic or psychological work that has hitherto not been identified in findomme observation. In this form of erotic commercial exchange, activities could be framed as moving beyond a leisure activity and towards a form of sex work. In addition to ready affirmation from likeminded individuals, communication via DPs ensures that findommes can manage self-presentation and participate, with great immediacy, in the use of social control mechanisms. The anonymity or adopted persona inherent in FD text-based interactions could facilitate a hit-and-run attitude towards more toxic behaviour and obviate feelings of responsibility (Suler, 2004). This has been shown to characterise many findomme linguistic postings regarding the control of 'sub' behaviours (Durkin, 2007). It remains to be determined whether the form of reward mechanisms that findommes experience during such interactions and whether adoption of a DP pseudonym may offset any feelings of 'emotional dissonance' (Ashforth \& Humphrey, 1993).

\section{Findomme Connections with BDSM Culture}

A previous cyber-ethnographic study of findomme culture by Durkin (2007) employed participant observation and content analysis of specific findomme websites, blog pages, and personal profiles. Much of the findomme vernacular identified in that study implied a connection to commercial BDSM identified in other studies (McLintlock, 1993; Cheng, 2013), but there was no open identification with this marginalised subculture. As in BDSM culture, findomme appellations (itself derived from the term femdomme or female dominatrix) suggest a subversion of the traditional roles of gender power and an image of dominant, sexual female. Conversely, pejorative 'subordinate' titles such as 'money slave' and 'money pig' engender and are thought to reinforce social control via their attributes of emasculation and subservience. Commercial sexual encounters involving BDSM are not confined to cisgender heterosexual encounters (Kolmes et al., 2006; Wright, 2006) as Grov et al. (2015) have shown in their research, based on data gathered from escorts, includes role play (dad/son, dominant/submissive). BDSM dominatrix names are also thought to facilitate boundaries, act as 'erotic capital' (Hakim, 2010), and facilitate the fantasy of role and power play subversion inherent in this subculture as the erotic construction of power ensues (Langridge \& Butt, 2005). Discourses within the BDSM community have also attempted to focus upon the issues of erotic gender power play (Cascalleira, et al., 2021; Williams, 2012) from its S/M component. A descriptive exploratory investigation by Williams et al. (2016) explored how bondage and discipline, dominance and submission, and sadomasochism act as recreational leisure. It is in the former exchange that findommes may arguably be seeking affiliation with the BDSM community, with the additional benefit of financial reward.

In a large systematic review, De Neef et al. (2019) explored the biological, psychological, and social knowledge about BDSM from 1970 to 2018. Their work contributes to the understanding and destigmatization of this form of sexual expression and challenge its place in psychopathological classifications. Many authors have argued that the hallmark feature that distinguishes BDSM activity from abuse and/or psychopathology is the presence of mutual informed consent of all those involved (Bezleh et al., 2012; Dunkley \& Brotto, 2020). Reviewers Dunkley and Brotto (2020) examined 
literature on consent in BDSM, including discussions on safety precautions, consent violations, North American laws pertaining to BDSM practice, and the role of the BDSM community with respect to education and etiquette surrounding consent. Their explicit approach to consent practiced by those in the BDSM community is proposed as a model for discussions around consent in other areas of sexuality, commercial, or otherwise (Dunkley \& Brotto, 2020).

The work of Lindemann (2013), however, directly deals with health and stigma within practices of erotic labour, and Lindemann (2013) used the commercial BDSM dungeon as a strategic research site to investigate workers' conceptions and management of their own stigma and found that discourses about stigma were inextricably entwined with concerns about health and wellbeing. Data were derived from ethnographic fieldwork with professional dominatrices ('pro-dommes') working in New York City and San Francisco as well as in-depth interviews conducted between September 2007 and April 2008. BDSM workers were not only concerned about safety but professionally invested in it, reinforcing it through an identity politics of hierarchies of erotic labour. The multiple implications of this work for public perception and policy implications could only be brought to light through the ethnographic method. In general, men cite their primary recourse to online sexual media, and communications is to aid sexual arousal (Cooper et al., 2000). The subtext to findomme activity is therefore suggested to be one of either psychological or sexual arousal for the money slaves through a findomme's demands. Conversely, findommes' motivations are identified as financial, and the research offers evidence for them using social control mechanisms via digital platforms to extract money. Early studies of striptease artists (Deshotels \& Forsyth, 2006; Wood, 2000) suggest, however, that it is the power over men, the 'rush' or thrill of the pursuit, and the ability to manipulate clients for money that are enjoyable and sometimes addictive factors for some female workers in this sector.

\section{Findommes, Stigma, and Social Learning}

The existing findomme literature highlights the vulnerability and stigmatisation of money slaves. Given what is known about stigma and its effect on working conditions (Benoit et al., 2017a, b), the punitive approach and effect on sex workers (Benoit et al., 2018) and its role in strategies and challenges sex workers face (Bungay \& Guta, 2018), are highly relevant to sex relations and the work of findommes on digital platforms. How sex workers manage enacted or felt that stigma may impose upon both their psychological and mental health (Garcia \& Crocker, 2008; Sanders, 2005a, 2008; Van Wesenbeek, 2005). The stigma associated with sex work has been shown to ostracise workers, impair their human rights, and ability to access legal, health, and psychological support mechanisms (BrooksGordon, 2006; Scambler \& Paoli, 2008; Ward \& Day, 2004; Jiaou \& Bungay, 2019). Stigma has also been shown to impair the ability to regulate and control one's actions (Inzlicht et al., 2006). Many individuals, however, develop strategies to fight stigma rather than internalising feelings of shame (Parker \& Aggelton, 2003; Koken, 2012; Koken et al, 2014). Whilst the existing literature focuses upon the fear of disclosure and shame of emasculation felt by straight male subs in paying for submissive activities, research attests, however, to the censorial attitudes meted out towards both sex workers and clients and which may subject them to ostracism within the wider community (Brooks-Gordon, 2006; O'Connell \& Layder, 1994; Ward \& Day, 2004). It is in the violation of cultural ideals regarding the exchange of intimacy for remuneration where all participants in financial domination might expect to experience difficulty in disclosing their activities outside of subcultural digital platform communities and trusted relationships.

An oft-applied model within the scant literature on financial domination as a means of understanding participation is the extension of the social learning theory of deviancy by Akers (1985). This determines that individuals with nonmainstream proclivities are able to exchange information, gain support, and rationalise their abrogation of socially accepted norms of sexual interaction. This may in turn serve to maintain their participation considering other negative reactions and promote in-group solidarity, and this has also been seen amongst cisgender and trans sex workers (Holt et al., 2010: Orchard et al., 2021). The use of various different digital platforms may require management to reduce client pressure and unwanted interaction and could be expected to shape behaviours of both findommes and their subordinates. Understanding the range of DP activities that financial domination encompasses is therefore central to understanding boundary maintenance and the potential for emotional and erotic labour that is inherent in all sex work (Chapkis, 1997; Sanders, 2004; Abel, 2011).

\section{Communication Strategies, Boundaries, and Risk Minimisation}

The findomme literature identifies text as a primary mode of communication. Morris and Feldman's extended model of emotional labour (1996) theorizes four dimensions: the prevalence of appropriate emotional display, the diversity of emotions that are displayed, attentiveness to required display rules, and the emotional dissonance experienced by having to display desired emotions that are not genuinely felt.

Using this model, it could be argued that it is the specific nature and intensity of emotions expressed during DP interactions that may be salient factors for findomme workers and the potential for emotional labour. Where activities are 
expected to move beyond the asynchronous nature of text and involve corporeal display through webcam smartphone communication, it may be reasonable to anticipate some degree of script and negotiation on the part of clients and findommes and which frequently forms the basis of face-to-face sex work (Sanders, 2005b). Separating one's visible online persona from one's 'vanilla' (non-FD) life may therefore require recognized strategies such as rituals of makeup and clothing to assume a 'work role'. Earlier ethnographic studies of phonesex workers (Flowers, 1998) highlighted the need for boundary maintenance and reduction of emotional dissonance even within a disembodied and anonymous environment. Humour and the operators' ability to manufacture an identity are emotion strategies in both FTF sex and phone-sex interactions (Flowers, 1998; Sanders, 2004). This indicates an effort to establish and maintain a distinct boundary between workers' public and private roles and to emotionally distance them from their client (Brewis \& Linstead, 2000a, b).

Adopting a work persona may, however, require careful management considering the inherent contradictions (O'Neill, 2001) and may result in emotional exhaustion from attempting to manage the duality of work/personal lives (Abel, 2011). In addition to voice divergence, phone-sex workers, like face-toface sex workers, may construct a persona and utilise highly scripted conversations linked to customers' fantasies and expectations (Flowers, 1998; Rich \& Guidroz, 2000). This obviates the need to infringe the personal moral code of the real self, protect personal boundaries, and may reduce sex work stigma. Phone-sex workers were shown however shown to experience pressure to change the boundaries of their sexuality and to manufacture emotions and behaviours in line with client fantasy. Determining whether FD activities limits itself to text-based activities is therefore an important consideration, since employment of webcam activity may frame it within the domain of a 'live' sex act and where erotic labour and the management of emotions in the course of work are thought to be implicit features (Abel, 2011; Chapkis, 1997; Jones, 2020; Sanders, 2005b).

The majority of FD work takes place at home and which may at first sight present suggest reduced risk to participants (Bernstein, 2007). This may promote undue haste into sexrelated activity and an overestimation of the remuneration, whilst negative social or psychological effects are poorly considered (Ray, 2007). Economic pressure might be expected to influence sex-worker boundaries (Sanders, 2005b) and increase the amount of emotional labour for the worker, dependent upon its expression, rather than its location (Hoang, 2010). As with direct contact, sex acts or acts of repressive humiliation via digital platforms may therefore require a range of strategies such as the adoption a 'work persona' if workers are to separate their work-self from their personal relationships, manage stress, and increase their marketability and income (Sanders, 2005b) or a form of labour duality (Bowen, 2021).

\section{Study Aims}

With notable exceptions (e.g., Benoit et al., 2017a, b, 2021; Koken, 2012; Koken et al., 2014; Scambler \& Paoli, 2008), scant previous literature has focused on erotic labourers' own perceptions of stigma and the ways in which regimes of stigmatization operate within their particular social worlds. Based upon the gaps in the existing literature, this research aims to clarify how findommes dictate and maintain their physical and psychological limits of interaction on digitally based platforms. This includes establishing how the findommes adopt strategies to manage emotional labour, avoid or handle stigma, and maintain their psychological health. This research follows the work of Chapkis (1997); Flowers (1998); Williams (2012) and Lindmann (2013) and takes the work of Williams et al. (2016) and (Campbell et al., 2019) as a starting point to examine contemporary erotic DP and, in particular, the microculture findommes and their perceptions and behaviour. A specific aim of the research is to establish some personal demographics as to who might be assuming this role, the range of activities engaged with, and findommes' motivations. Further aims are to establish how findommes engage and maintain the physical and psychological limits of their activities, and whether they manage and use their emotions during interactions.

Sex workers returning to work require more financial support following the pandemic (Callendar et al., 2020), and many are likely to stay with, or turn to, working via digital platforms rather than return to pre-pandemic modes of work. As the policies of some police forces, and political parties, increasingly progress towards harm reduction (BrooksGordon et al., 2017; Brents \& Sanders, 2010; Sanders et al., 2020), it is important to understand the world of findommes in more detail. This will help answer wider questions raised by the literature, for example, whether findomming is more likely to attract those already part of the BDSM community and are attracted to the work, or whether those already in sex work transferring to the area of domination which is known to be a more highly paid area (see Brooks-Gordon et al., 2015). A final objective of this research is therefore to establish whether findommes experience stigmatisation during their activities and how they manage any hitherto unidentified psychological barriers in the course of their work.

\section{Methodology}

\section{Stage 1}

A mixed methodology approach was used because data from multiple perspectives facilitates deeper exploration and comprehension (Frost et al., 2010). An online survey was used to gather categorical data on personal demographics 
of geographic location, age, gender, sexual orientation, relationship, and employment status-population which is sparse in the literature on findommes. In addition, several open-ended questions were asked about respondents' motivations for participation in money slavery, and positive or negative aspects to their work. The phrasing of questions recognised the need to minimise bias, social desirability, leading questions and value judgements. The survey was limited to findommes and advertised on a range of social media sites. This method enabled voluntary participation, and a pilot survey ran for a period of 2 weeks, and minor adjustments were made in phrasing to ensure greater clarification and speed of response. The demographic data was gathered using the survey builder on SurveyMonkey®. The open-ended responses were analysed qualitatively.

\section{Stage 2}

This stage consisted of observations gathered from 195 findommes across seven findomme websites, and samples gathered from 40 postings to the blog page and four longer 'real-time' virtual communications with findommes. Using cyber-ethnography first pioneered by Roberts et al. (2004) and Kozinets (2010) and now established as netnography (Heinonen \& Medberg, 2018; Kozinets \& Gambetti, 2021) as a tool for online research, we initiated the research process in 2014 via passive observation and information from seven money-slavery websites and Twitter feeds. The primary approaches are qualitative and ethnographic. A social constructivist approach allows that participants are active in recounting and founding their reality. Feminist discourse (Chapkis, 1997) regards these as applicable and sensitive methods for answering questions and generating theories regarding the experiences of female sex workers and responding to their inequalities.

Data collection, therefore, employed multi-modal cyberethnography in order to understand motivations in the light of dynamic social processes and differing social contexts. Participants' realities were explored in terms of the microand macroenvironment, their public versus their private lives, and findommes' collective and individual experiences. This approach increased ecological validity by allowing for the triangulation and 'linking' of data with which to generate theory. The research was initiated via passive observation and the gathering of field notes from seven money-slavery websites and Twitter feeds. Using an approach inspired by grounded theory (Glaser \& Strauss, 1967), the data was axial coded, and then, a content analysis approach was employed to the setting up of a money-slavery blog and Facebook page. This was achieved by posing a series of open-ended questions on the themes relating to findomme activity including the management and setting of personal boundaries, feelings regarding the disclosure of activities, and the management of emotions during the course of their work and enabling participants to offer their written responses to the blog and Face book page voluntarily. Participants chose to either remain anonymous or employ a pseudonym. Enabling anonymity of participants reduced the need for self-presentation by the participant and response to the structure of power between the researcher and the participant. Whilst acknowledging the issues of self-presentation that are inherent in social media, author A became a participant/observer on Facebook to allow for both asynchronous and real-time synchronous interactions with findommes and also observations of findomme/money-slave interactions. The survey page, blog, Twitter, and Facebook sites were hyperlinked to each other in order to enable dissemination of information and maximise voluntary participation at a national and international level. Quotient sampling has been used to analyse all of the qualitative data and to ensure parity of representation.

\section{Procedure}

Data was gathered on a blog, survey, Facebook page, and on dedicated findomme websites under the pseudonym of 'Rachel Reader'. This was done to create a virtual identity that was non-threatening to participants, but which also served to protect from any potential negative repercussions of disclosing personal details. This pseudonym was openly declared on all research sites and in all communications with participants. Trust and rapport are integral elements in research via digital platforms and, according to Sanders (2005a, b), need to be established quickly. In declaring Rachel to be 'female', we also added that she was a mature student. This was an important consideration designed at reducing the hierarchy of the participant/respondent relationship, whilst establishing the position as a dedicated, but 'naïve' researcher.

\section{Specific Findomme Sites}

Researchers are increasingly disclosing their membership identity in the communities they research, as Angrosino (2005) observes. Using the declared research persona, we gained permission to advertise the research and postresearch questions of specific findomme websites. We also employed passive observations of findomme and moneyslave interactions and kept a series of coded and dated field notes.

\section{Survey and Facebook Page}

On the Facebook site, the first author acted as active participant/ observer and maintained an open access profile under the research pseudonym of 'Rachel Reader'. Participation was voluntary. Findommes were able to message confidentially 
on the Facebook site or via a supplied email. We allowed a cooling-off period for participants to review their comments and ensured that permission was sought before using any comments. All text-based communications were coded to ensure names, and profiles could not be matched to participant comments. Facebook links from individuals were limited to those over 21 years of age and prohibited where fraudulent identity was suspected. In adopting a policy of informed consent, we did not engage in researching participants who declared themselves to have mental health difficulties or communicate with them whilst they stated themselves to be under the influence of alcohol/prohibited substances. Where this was later revealed by two participants, we employed a policy of 'self-censorship' (Lee, 1999) and removed their contributions in order to respect this additional vulnerability. Participant observation is on a continuum of activity, and to maintain more of an observer than participant status, a quiet presence was maintained on Facebook, and we did not comment or respond in a way that might approve, or serve as judgement on, various activities.

\section{Wordpress Site and Blog}

Contributions to the Wordpress site and blog were voluntary, and participants were requested to sign a consent form and age declaration before posting. As a public site, comments from participants were screened to protect the respondents from potential harassment or stigmatisation. All posted comments and responses were screened individually approved before appearing on the site.

\section{Ethics}

Each site explained the research objectives, how information would be used, ethical approval from the institution, contact details of the researchers, and information on withdrawal from the study. All survey participants were recruited on a voluntary basis, and no individuals were emailed directly. Questions were screened to reduce any discriminatory biases around race, disability, or sexuality and minimise potential feelings of jeopardy or stigma (Lee, 1999). Participants read the research declaration before progressing to sign a permission form declaring they were over 18 years of age and their consent to take part in the survey. Participants chose their pseudonym at this point. The survey permitted participants to opt out of any questions they did not feel comfortable answering. Access to survey responses was limited to the researcher via a code name and password. As a pseudonym may contain elements of a subject's real name (Roberts et al., 2004), all printed data and field notes, were recoded and then locked in the researcher's filing cabinet. Stored computer information was protected by a subsequent password and security system because ethnographers need to be able to respond to the multiplicity of digital platform methods available, whilst applying standardised principles of protection for their participants in a digital environment that has diverged from the face-to-face research for which guiding ethical principles were designed (Cora Garcia et al., 2009). Critical to our concern was the opportunity for demarginalising the voice of stigmatised communities (Murthy, 2008) and with self-reflection comes the need to be aware of the embedded hierarchical position of the researcher. The stigma to which female sex workers are subjected means that it is important to adopt data collection methods that are non-exploitative, giving respondents control, and which permitted us to 'enter the common sense world' of those being studied and document it. All questions were designed to reduce the probability of distress to participants, and we also employed the voluntary service of a personal counsellor in the event of participants recounting any distress.

\section{Reflexivity}

The role of McCracken as a passive participant observer was a challenge to manage researcher/participant levels of selfpresentation. Active digital platform ethnography of sexual subcultures can result in exposure to unwanted imagery, unwitting social consolidation of participant behaviours, and the need to provide psychological support outside of the research brief. Careful consideration and planning for these are risk management factors in active cyber ethnography, and successfully negotiated mean research can benefit from participant observation rather than mere observation. As a non-participant in FD, researcher A acknowledged her position as a mature, heterosexual cisgender female, her role as a 'naïve' researcher and lack of first-hand knowledge regarding FD, and sex work on digital platforms. In considering these factors and the need to overcome the potential for power imbalance between the researcher and participants, researcher A worked under a pseudonym but was transparent about these factors of her identity in order to encourage a more reciprocal experience. Additionally, she maintained detailed study notes that enabled reflection and monitoring of one's own interactions and observations for any preconceived ideas, biases, and enacted stigma regarding digital platform sex work, FD, and the BDSM community.

\section{Results}

The analysis is set out in two sections where the first presents the survey results and the second section presents the data from seven findomme websites, the findomme blog site, and Facebook page (including 'real-time' conversations held with findommes on Facebook). 


\section{Stage 1: Demographic Analysis and Survey Findings}

A total of 56 participants responded to the online survey although not all questions or categories were answered by all participants. Table 1 shows the number of responses $(n)$ in each category and its percentage calculation corrected to one decimal place.

Table 1 shows survey results (a) Geographical location of survey participants responding. (b) Declared gender status of findommes. (c) Age range of FD participants. (d) Sexual orientation of findomme participants. (e) Declared relationship status of participants. (f) Number of participants with children under the age of 16 years. (g) Participants' additional employment status. (h) Participants' motivation for carrying out financial domination (categories not mutually exclusive). (i) Range of activities being carried out by participants online at the time of survey. (j) Range of activities being used or considered by participants at the time of survey.

The data in Table 1 (a) shows that participants were predominantly from the United Kingdom $(n=33)$ and the USA $(n=13)$ and that participation in FD took place in Europe, Australia, and Asia $(n=7)$. Participants' declared gender status is illustrated in (b) and most participants identified as cisgender female $(n=35)$ or male $(n=18)$ with only one transgender respondent $(n=1)$. Our survey findings (c) indicate that most participants were between 18 to 28 years of age and that activity continues for findommes into their fifties. Most of our respondents were heterosexual $(n=42)$, but Table 1 (d) shows several participants were bisexual $(n=10)$ or gay/lesbian $(n=2)$. In terms of relationship status (e), $40 \%$ of participants were single, whilst $33 \%$ of participants declared themselves to be either married or cohabiting. The majority of participants $(n=41)$ had no dependants under 16 years of age, but approximately $24 \%$ had them which can be seen Table 1 (f). Approximately $46 \%$ of findommes were in full-time employment and a further $54 \%(n=29)$ in either part-time work or studying full or part time as students whilst the remainder (13\%) were unemployed, as seen in Table $1(\mathrm{~g})$. For the majority, FD offered an income to fund a specific chosen lifestyle in Table 1 (h); interestingly, many respondents $(n=28)$ chose not to disclose their reasons for participation in FD, whilst for others, it was the payment of university or college fees and loans, or financial hardship that was the primary motivation. To the open response question, twenty cisgender female respondents cited attention, personal power, work flexibility, money, and gifts as positive aspects of the work, and some participants indicated that they felt 'addicted' to the 'buzz' of receiving such items through the post. The findommes declaring their range of DP activities in Table 1 (f) were exclusively female $(n=45)$ and were actively engaged in a range of digital platform-related activities paid for by their money slaves. Most respondents used flirtatious and erotic language and also included 'dressing up' in desired
Table 1 Survey findings and demographic results of findommes $(N=56)$

\begin{tabular}{|c|c|c|c|}
\hline \multirow[t]{6}{*}{ a } & Region & $N=53$ & $\%$ \\
\hline & UK & 33 & 62.3 \\
\hline & USA & 13 & 24.5 \\
\hline & Europe & 4 & 7.5 \\
\hline & Australia & 2 & 3.8 \\
\hline & Asia & 1 & 1.9 \\
\hline \multirow[t]{4}{*}{ b } & Gender & $N=54$ & $\%$ \\
\hline & Male & 18 & 33.3 \\
\hline & Female & 35 & 64.8 \\
\hline & Transgender & 1 & 1.8 \\
\hline \multirow[t]{6}{*}{ c } & Age range in years & $N=54$ & $\%$ \\
\hline & $18-28$ & 31 & 57.4 \\
\hline & $29-38$ & 13 & 24.1 \\
\hline & $39-48$ & 8 & 14.8 \\
\hline & $49-58$ & 2 & 3.7 \\
\hline & $59 \mathrm{yrs}+$ & 0 & 0.0 \\
\hline \multirow[t]{4}{*}{ d } & Sexual orientation & $N=54$ & $\%$ \\
\hline & Heterosexual & 42 & 77.8 \\
\hline & Bisexual & 10 & 18.5 \\
\hline & Gay/lesbian & 2 & 3.7 \\
\hline \multirow[t]{6}{*}{$\mathbf{e}$} & Relationship status & $N=52$ & $\%$ \\
\hline & Single & 21 & 40 \\
\hline & In a relationship & 13 & 25 \\
\hline & Married/cohabiting & 17 & 33 \\
\hline & Separated/divorced & 1 & 2 \\
\hline & Widowed & 0 & 0 \\
\hline \multirow[t]{3}{*}{ f } & Dependants under 16 yrs & $N=54$ & $\%$ \\
\hline & Yes & 13 & 24.1 \\
\hline & No & 41 & 75.9 \\
\hline \multirow[t]{5}{*}{$\mathbf{g}$} & Employment status & $N=54$ & $\%$ \\
\hline & I work full time & 25 & 46.3 \\
\hline & I work part time & 14 & 25.9 \\
\hline & I am a student $\mathrm{P} / \mathrm{T}$ or $\mathrm{F} / \mathrm{T}$ & 8 & 14.8 \\
\hline & I am currently unemployed & 7 & 13.0 \\
\hline \multirow[t]{5}{*}{$\mathbf{h}$} & Motivation & $N=38$ & $\%$ \\
\hline & To fund chosen lifestyle & 22 & 79 \\
\hline & To pay uni/college fees & 6 & 21 \\
\hline & Financial hardship & 3 & 11 \\
\hline & Other reasons & 7 & 25 \\
\hline \multirow[t]{4}{*}{ i } & Online activities include & $N=45$ & $\%$ \\
\hline & Flirtatious/erotic language & 24 & 92.3 \\
\hline & Dressed up & 17 & 65.4 \\
\hline & Other* & 4 & 15.4 \\
\hline \multirow[t]{6}{*}{$\mathbf{j}$} & Activities & $N=56$ & $\%$ \\
\hline & Online messaging & 29 & 96.7 \\
\hline & Webcam/Skype & 25 & 86.7 \\
\hline & $1: 1$ meeting & 17 & 56.7 \\
\hline & A physical relationship & 5 & 16.7 \\
\hline & Real time & 1 & 1.7 \\
\hline
\end{tabular}


costume as part of their work. The data gathered in Table 1 (i) also shows most participants $(n=56)$ use some form of DP messaging and corporeal display via webcam as part of their repertoire. Some of these $(n=23)$ were considering a progression to meeting clients on a 1:1 basis or taking part in a physical or 'real-time' domination session. One participant indicated, however, that money slavery might also include 'just talking' to a client. There was no indication to suggest that any findomme activities, even on a 1:1 real-time basis, included sexual intercourse. Some findommes indicated feelings of stigma at being associated with sex work and the verbal abuse meted out by clients. All participants cited negative feelings when men tried to obtain free services.

\section{Stage 1: Qualitative Observations and Conversations}

This section represents observations gathered from 195 findommes across seven FD web pages, samples gathered from 40 postings to the blog page, and four 'real-time' DP communications with findommes.

\section{Key Motivations}

In line with survey findings, many of our participants stated that a key motivation for FD was financial remuneration. Some participants felt that they were not dependent upon the income but stated that FD provided an opportunity to enjoy additional income or luxuries for them or their families. As one participant 'PA' states:

'... if it didn't pay well I wouldn't do it, I think I'll be doing it for the foreseeable I see it as just work, it pays bills and I have no qualifications so its easiest job to get as well....' (PA).

For such participants, financial domination represented a move from other forms of online sex work and was a rational choice due to her limited educational opportunities. Several women said that FD provided positive choices in terms of meeting childcare arrangements and they considered FD as 'work' rather than a lifestyle or leisure activity. One woman elaborated:

'The money makes one feel loved and special, a lot is due to lack of confidence, the feeling of not being loved-the attention is what is addictive, not necessarily the gifts.' (R).

Other participants stated that their initial motivations were fiscal, but that this was now secondary to the feelings of power and control it gave them. Many identified strongly with the archetype of a dominant and superior female and were deeply critical of those findommes whom they regarded as not adhering to this model.

\section{Interaction with Other Microcultures}

For other participants, especially those who belonged to stigmatised communities such as transgender women or those with disabilities, operating within the online FD community meant that they were able to disclose information to an equally stigmatised community, or microculture, and receive opportunities for adoration and acceptance from a wide range of online 'subs'. One participant stated that FD counteracted her experiences of childhood bullying and that the attention, in-group social consolidation, and acceptance had been empowering for her. The majority of participants identified with FD as a legitimate albeit demanding form of work, but one that ran counter to prior expectations of the work. One participant noted:

'This is a full-time job on its own D: more so than a vanilla job because it never ends, the messages are 24/7! Yes that's another side to it, a lot of these men are addicted to paying girls. It can be a very dangerous addiction too, right? The newer girls don't get that and then you get the others that don't care about that. I think it's an addiction on both sides though. I' $m$ definitely addicted to this lifestyle and have been for 4 years now.' (S).

In this way, participants acknowledged that the work carried a component of emotional risk for both clients and findommes and were deeply critical of what they termed'instadommes' or women/men entering the scene for purely temporary and financial factors.

In addition to field observations, the participants responded using text-based conversation and web-based communications in their work. They confirmed that work was often psychological but also elicited sex arousal on the part of money slaves. As L mentioned: 'Most will just be sat there and of course majority are masturbating or indeed in a state of arousal'.

Observations of findomme/client interactions confirmed that activities were not restricted to male clients. Several findommes had cis and transgender women who were slaves under their financial supervision. Interactions between female dominants and female subs appeared to differ in that findommes often assumed the role of a controlling and superior older sibling or 'mother'. Several respondents referred to their domme as 'Mummy' and interactions generally involved high levels of social control but reduced levels of humiliation. Distinguishing appellations appeared to be a first step for our participants, in determining a work persona and individual work boundaries, for example, one explained:

'If a sub call's you Mistress as soon as he requests to speak with me, gives me an impression it's understood who has the upper hand and that he knows his position, I like to start as I mean to go on' $(\mathrm{H})$.

Establishing work boundaries was mentioned, but financial remuneration played an important part in choice of interactions, and this empowered the sub or money slave: 'it's their choice at the end of the day, because they're the one that could cut off your money and gifts at any point, so when they want to ditch you, they will' (B). 
The observations and interviews with research participants indicated that, whilst Findommes were able to turn down activities that were distasteful to them, financial remuneration might influence the boundaries of their work. One participant described the work contract as a constant 'push, pull' of negotiation in meeting clients' needs and adherence to boundaries. She explained:

'I have felt negative emotions a bit this lifestyle (sic) from time to time when it's obvious to me that the men are trying to bribe me to take pictures or get on webcam in exchange for their money. The lifestyle is about the man's desire to pay me, not about his desire to pay me for an exchange.' $(\mathrm{J})$.

This response by ' $\mathrm{J}$ ', however, typified findomme beliefs regarding money slavery in that the relationship is deemed to be based upon a wish to spoil or indulge the domme, rather than upon the purchasing, however, negotiated, of a service. In this sense, money slavery could be regarded as fundamentally different from commercial BDSM services because there is no guarantee of the client being offered anything other than her online engagement. Many of the postings by findommes indicated resentment and anger at client assumptions regarding the purchase of services and emphasised the ideology of voluntary servitude. One participant stated that, where younger or inexperienced workers entered in FD, it was very easy for them to be manipulated by client demands, particularly where money, rather than the lifestyle, was a motivating factor. Despite her emotional dissonance regarding the work, one student participant who had initially limited herself to text-based interactions and erotic language had, during the 3-month research period, moved towards offering web-based services of striptease for male clients.

The DP environment did not inhibit or protect workers from potential clients trying to dictate or extend the boundaries of an agreed relationship. Many participants mentioned or were observed receiving unwanted and highly sexualised personal images. Whilst this was one of the most challenging aspects of their activities, they managed this behaviour and their feelings with shared humour (Sanders, 2008) and the support from other DP findommes. Many participants experienced 'time wasters' seeking unsolicited free contact in addition to interactions, and two participants stated that, because they felt their activities were legal, they felt able to seek legal support whenever they were harassed. They advised, however, that findommes should take care over the setting of work boundaries and the disclosure of any form of information that would enable clients to trace them.

\section{Stigma}

In line with survey findings, the interview findings and field observations indicated that, even where their activities may not be visible, findommes also experience stigmatisation regarding their work and were keen to separate their work from sex work. One described her work thus:

I'm a Financial Dominatrix. Every fetish I'm involved in is operated by my DESIRES. I don't do FREEBIES. I don't ESCORT.I'm not a prostitute, and I don't care how much money you offer me, I won't HAVE SEX WITH YOU. ...... (SA).

Various participants attempted to assuage feelings of both enacted and felt stigma and associations with prostitution by identifying with the subculture of fetish and BDSM. Paradoxically, much of 'real-time' BDSM regards commercial BDSM work, and specifically FD as being extortion and something that offered very little in way of service to clients. Where workers' moral codes conflicted with FD activities, some participants experienced emotional dissonance and 'felt' stigma. One participant stated:

"I feel (now)... ashamed. I don't talk about this stuff anymore. But at the same time, it did exactly what it was supposed to do. ..." (RS).

Another responded concurred: 'The negatives are keeping my job a secret from certain people for fear of judgement: worry about what to put on the resume; general feeling in society that sex work is immoral.' $(\mathrm{K})$.

In identifying online financial as a form of sex work, respondents advised that one of the most negative aspects of the work was the secrecy involved, and participants were often subject to 'enacted stigma' via postings from noncommunity members concerning their'rinsing' of clients for money and aligning them to fraudsters by taking advantage of individuals. Some participants gave accounts that stated that their activities constituted female empowerment or offered a professional service that was supported by others. Stigma was managed in some cases by the ability to disclose FD activities openly with friends and family members: "My boyfriend and even my mom know about it. They both agree and support me' (G).

Some FD postings contained pictures of family members mimicking many of the language and gestures adopted by findommes. Even without the 1:1 sexual encounter, some participants still felt the stigma of being associated with any form of paid DP sex or fetishized work and felt unable to disclose their work with all but the closest of peers or family. The felt stigma encountered by several participants was, however, offset by what they regarded as the very positive aspects of their work. In addition to receiving increased financial stability, several participants commented that they felt empowered by the attention and control their DP work offered them.

Participants uploaded images of themselves pictured with handfuls of money supposedly given by money slaves or by gift boxes from admirers. Other findommes indicated that it was not unusual to fabricate or exaggerate the extent of clients' gifts to promote the image of success and to manipulate and control clients, as one highlighted it thus: 
'I also find that the girls are very deceitful about how well they do J and E (I feel like a little sneak!) are two in particular who have a habit of fibbing about who they own and what they earn...' (B).

Findommes modelled and managed money-slave behaviour by posting humiliation lists of those who failed to offer appropriate levels of financial 'tribute'. These humiliation lists frequently garnered social support, and we observed a heightening and intensification of new findommes' language during the 3-month research period. In addition, positive behaviours were publicly rewarded, and this elicited their continuation and gave examples of the desired modes of interactions to inform other clients and inform other findommes.

\section{Managing Emotions}

The psychologically intimate nature of the work meant that findommes did need to manage their emotions, and this was assisted by the physical and geographic distancing of the DP exchange, as one explained to her how she manages this:

'Whether it's during or after, the aim of it is generally sexual relief, for them'. I wouldn't feel comfortable having someone wank at me in person. I'm not sure why, but that's a little too close to prostitution to me, even though they wank online anyway. But, I don't watch it if I don't want to, which I generally don't.' (LL).

Participants also said they frequently dressed up in stereotypical costumes of the 'dominant' female or 'princess' whilst online-and were observed in these costumes in their online postings- to 'manufacture' an identity that was distinct from their 'vanilla' persona. Eighteen of the participants interviewed confirmed the survey findings in that they engage in both' surface' and 'deep acting' and the creation of a work persona which helped to manage their emotions, as one respondent stated:

'I find its completely not me being myself once I' $m$ as I'd say working, its hard to explain but it's a bit like acting, u just know you have to talk act different, its what they expect, I'm just a normal average mother they wouldn't give me time of day being my usual self, so its easy for me to just think right im someone else now..... u do have to be in humour to do it. some days it would b nice to just b myself' (PA).

The physical separation of the DP enabled some workers to engage with 'surface acting' and the manufacturing emotions in accordance with the role, whilst not fully identifying with it. 'PA's responses exemplify how surface acting is flipped on or off as the situation requires. For ' $\mathrm{L}$,' however, a more financially independent findomme, the work involved a process of 'deep acting' and an identification of herself as a 'carer'. This strategy is evidence that, by adopting a persona, she was able to manage some of the more challenging areas of her work and focus on its more positive aspects, as she explains:

It's very strange but when you have been doing this for so long you just become desensitized to it and it almost doesn't feel strange at all. Just like a carer wiping someone's bottom I guess! .... Sometimes you can be their only person in the world they can open up to so you're almost like a therapist! (L).

The adoption of an authentic virtual persona was not always sufficient in disassociating from or managing feelings towards the more distasteful aspects of their work. One participant shared her feeling of emotional dissonance. In reconciling her 'domina' personality and her 'softer side', three participants reflected on the difficulties of coping with clients' verbal aggression, and in some cases, suicidal tendencies. Some participants were able, however, to employ strategies such as engaging quickly with their own children or other family members to distance themselves from the emotional demands of their online activities.

By viewing the work as more of a lifestyle or a helping role, various findommes were able to separate work/online activities and counterbalance the demands of emotional labour with the freedom for self-expression and financial rewards it offered. As ' $L$ ' said:

'I love what I do. I offer a much-needed service to people who require it. Occasionally I feel sorry for slaves, as I am certain they just need a good friend or a hug. Others live out a fantasy or fetish with my help, which is totally separate from day-to-day life. ... But when the work is done, it's done. Back to the ironing!.' (L).

In this way, they were better able to develop a sense of balance and wellbeing.

\section{Discussion}

The analysis shows that the phenomenon of financial domination is geographically widespread and reflects a consensual, commercial arrangement of role-play and humiliation activities, designed to elicit both psychological relief and sexual arousal for the money slave. The breadth of respondents' geographical participation supports the literature showing that the internet as a social consolidation mechanism that collapsing geographical divides that enables communication with others of similar interests and to gain support (Durkin \& Bryant, 1995). Most participants had no dependants under 16 years of age, but for the quarter of participants who did participation in FD may therefore present a rational choice for the payment of childrearing costs. This also may place an additional burden on some participants to hide their activities. More than half 
the participants were either in part-time work, a studying, or unemployed, and for these, financial domination also represents a rational choice as a means to earn what can amount to a substantial amount of money from the privacy of their home, whilst meeting the demands of college or university fees, caring responsibilities, or reduced educational opportunities. The ability to work from home and earn a comparatively high income may represent, however, a rational choice for the participants who declared their motivation to be financial hardship or to pay tuition fees. Research has indicated increasing acceptance of sex work by students as a means of coping with financial difficulties (Roberts et al., 2004). The participation of overseas and UK students in this research may also reflect the evidence gathered for worker rationalisation of sexual commerce as a means of paying for tuition fees, rather than accruing substantial debt, and of the mainstreaming of the sex industry (Brents \& Sanders, 2010).

The findings showed that several findommes had cisgender female and transgender women slaves under financial supervision. These findings extend the existing research literature on money slavery (Durkin, 2007) where interactions were primarily between cis gender women and men. Whilst demographic analysis indicates that findommes are predominantly cis gender women, it also suggested that dominant and subordinate roles may be assumed by all gender statuses and sexual preferences and that a wide range of ages participate in findomme work which supports the work of Grove et al. (2015).

\section{Progression of Findomme Communications}

This study reveals that FD activity is initiated with the use of text-based communication and progresses to include DP face-to-face and voice communications. This was not only personal preference but also subject to commercial negotiation and indicates that, for some participants, FD signifies a 'live 'sexual or erotic exchange. Although FD clearly elicits sexual arousal for clients, the relationship can also be exclusively psychological and focus on the relinquishing of control to a money mistress for a prescribed period before returning to 'normal' activities and relationships. Female dominant/female slave relationships may see the subordinate seeking a dominant cis gender female superior as a form of mentor or authoritative 'mother' figure. Those participants were using online messaging, and corporeal display via webcam extends the existing research literature (Durkin, 2007) and suggests that, for some participants, FD activity could be framed as a form of visible DP sex work and where both participants may be visible rather than anonymous. This may have implications for the maintenance of work boundaries and the employment of emotional labour.

\section{Motivation Matching}

Findommes' motivation appears to be the subject of much debate even within its own community websites, and whilst FD involves commercial exchange, it also represents a lifestyle and offers opportunities for experimentation and role play as a 'dominant'. Some findommes identify with the BDSM ideology of an erotic power exchange and distinguish their activities as being highly skilled virtual fetish work, which may, in turn, lead to face-to-face domination of clients. For these participants, it was the matching of the findomme motivation of payment with client desire for submission that underpinned the success of the relationship, rather than the actual amount of money being transferred. This research offered empirical evidence that attention, the ability to control others, and feelings of self-empowerment are also important motivations and may also represent reasons for prolonged findomme activity. For many findommes, however, like other forms of sex-work, it is strictly entrepreneurial (Sanders, 2005a) and represents the ability to use erotic capital (Hakim, 2010) to supplement income by catering to a very specific population of predominantly cis gender male clients who seek non-conventional relationships that cannot be fulfilled by partners. On the open response question, twenty female respondents cited attention, personal power, work-flexibility, money, and gifts as positive aspects of the work, and some participants indicated that they felt 'addicted' to the 'buzz' of receiving such items through the post. These findings add to the existing literature on FD motivation and suggest that attention and power may be supplementary factors to FD motivation. Whilst commercially driven, the boundaries between financial dominations being a lifestyle activity and sex work were not explicit and were negotiated in a variety of ways. The research literature (Deshotel \& Forsyth, 2006) identified that power, feelings of enhanced desirability, and manipulation in the pursuit of money were important for findommes. The component of emotional risk for those entering the work for purely financial reasons and who, as research has identified, may be poorly prepared for its psychological demands (Ray, 2007).

\section{Bounded Authenticity}

This cohort encompassed some skilled participants that Bernstein (2007) once identified as a 'more middle-class, educated sex worker', who, considering gendered and economic disparities, choose to engage in sexualised labour due to its financial incentives. In such cases, the apparent anonymity of the findomme persona may seem to be an attractive option since it may signify the opportunity to gain commercial goods and money for a minimum of sexual interaction and which can be more readily compartmentalised from other day-to-day activities. In both 
direct and non-direct communications, findommes were observed and reported to be in active negotiation in what Bernstein (2007) refers to as the 'bounded authenticity' of an authentic yet bounded interpersonal connection in terms of the physical and emotional content of their services. The commercialisation and negotiation of activity indicate that the titles of dominatrix and 'slave' may sometimes be a misnomer, which reflects some of the dynamics identified in commercial BDSM relationships (Williams, 2012). The dominants declaring their range of DP activities were exclusively female and were actively engaged in a range of digitally based activities paid for by their money slaves. Most respondents used flirtatious and erotic language and included 'dressing up' in desired costume as part of their work. This may indicate the adoption of a work 'persona' (Sanders, 2005b) and emotional labour to separate work and personal lives and meet client demand.

\section{Negotiations and Maintenance of Boundaries}

The psychological implications and pressure to extend sexual boundaries (Megan Smith, 2017) are important considerations, however, for those who may enter sex work under these conditions. These findings may also indicate hidden population of sex workers who would benefit from additional support or consideration in their lifestyle choices. As in direct contact sex work, findommes may refuse activities they feel are distasteful, but fiscal considerations may in some cases exert considerable influence in the willingness to fulfil clients' desires and maintain their loyalties (Sanders, 2005b). Wilson (2005) advises that, even with the commercial BDSM community and the suggested dominant/slave relationship, workers may have intense negotiations with clients regarding the scripting of role play. By identifying with and observing the unwritten rules of not poaching other findommes' money slaves, participants were able to utilise in-group solidarity to both monitor and control unwanted aggressive 'out-group' behaviours whilst enacting their own specific identity and gain acceptance and respect. Group identification and support were also important mechanisms for managing the stigma attributed to findomme activities.

This research challenges the hegemonic discourse in previous findomme research (Durkin, 2007) of the exploitative female dominant and the 'victim' male client to some extent. In this research, there was evidence for example, of younger, less experienced findommes being pressurised to extend boundaries of text-only interaction, to include web-based work involving full frontal nudity. Findommes' agency increased where they asserted their lack of financial dependency and their entitlement to it as dominant females. Assertions of financial independence also acted as a form of erotic capital enhancing personal status and earning potential (Hakim, 2010). Even within the context of text-based interactions, clients' behaviours appeared to follow traditional scripts of sex work (Sanders, 2008) and a desire to move towards an established and defined relationship with their findomme. Maintaining the boundaries of an agreed relationship and reinforcing clients' awareness of fantasy/real life often required considerable emotion work for findommes. Findommes, in general, may elicit very high levels of emotional stress and verbal aggression from clients who experience difficulty in reconciling the fantasy of their expectations with their real lives and the limitations of the DP relationship. In this sense, operating within the digitally based world does not necessarily safeguard findommes from client's preexisting relationship scripts, their desire to re-enact them, and the psychological demands of negotiating them.

Participants appeared to be able to reconcile the ideals of monogamy that underpin contemporary notions of relationships (Giddens, 1992) with the use of erotic capital (Hakim, 2010) and often highly sexualised interactions with clients, and they did not report conflict in their own relationships as a result. Whilst the physical boundary of DP work may separate and support online/offline boundaries, it does not preclude the employment of emotional labour and the need for emotion management. As with direct sex work, the adoption of a work persona in the authentic DP persona developed by participants played an important role in mediating and maintaining work/life boundaries (Benoit et al., 2017a, b; Bernstein, 2007; Sanders, 2008; Suler, 2004).

\section{BDSM}

Many names indicated FD's affiliations with BDSM ideology in that they frame the male/female dynamic and establish a psychosexual contract (Wilson, 2005; Palandri \& Green, 2000; Brown et al., 2020; Cascalleira et al., 2021). Role-play names may also indicate the adoption of a work/ online persona as a protection strategy to facilitate an emotional distance between them and their client and enhances work/life separation and their professionalism (Abel, 2011; Flowers, 1998; Sanders, 2005b).

\section{Social Learning, Social Support, and Reinforcement}

Findommes modelled and managed money-slave behaviour by posting humiliation lists of those who failed to offer appropriate levels of financial 'tribute' and which frequently garnered social support This supports theories of a socialidentity model in that our participants' verbal displays also served an additional function in terms of maintaining respect and in-group solidarity and supporting models of social learning theory by Akers et al. (1997). This research lends support to the findings of Durkin (2007) in establishing that findommes make extensive use of social control 
mechanisms to model and reinforce the etiquette of interaction and exchange with 'subordinates. Social learning theory (Akers, 1985) was also found to be an applicable model for explaining some behaviours in that both findommes and money-slaves' behaviours receive mutual reinforcement. For money slaves, offering money elicits praise, psychological and sexual relief. In addition to receiving the adoration and attention from money slaves, findommes were able to draw upon extensive support and affirmation when carrying out punitive sanctions such as blackmail, humiliation, and verbal aggression on clients during their web page postings. This also includes support from other findommes and other 'subordinates' seeking to model and seek affirmation for their own adherence to desired 'sub ' behaviours. The survey findings lend support for social learning theories (Thomas et al., 2010) and differential reinforcement whereby behaviours are strengthened and may persist through reward mechanisms of significant others and where positive and neutralising definitions of actions may serve to offset negative ones (Akers et al., 1997; Abel, 2011).

\section{Emotional Labour and Occupational Safety}

Our findings indicate that findommes employ emotional labour and management of their emotions (Chapkis, 1997; Hochschild, 1983; Sanders, 2005b) in carrying out their interactions with money slaves. The frequency and nature of interactions have been highlighted as important factors in the extension of models for emotional labour and considering the evidence for the rapid, frequent, and intense communications that underpin findomme activity. Participants gave accounts for their work as being a form of 'caring' or therapeutic profession, envisaging themselves in some cases as being the client's sole mentor. Other respondents were pragmatic and indicated that, for them, their online findomme persona was not disassociated from their 'vanilla' personality, but an extension or sometimes better version of it, which made them feel empowered. Survey respondents in this grouping reported higher levels of satisfaction regarding their activity and a healthy separation between digitally based and offline activities.

Respondents counterbalanced the demands of their work life by engaging rapidly in normative activities of childcare or housework to disengage and switch off from the emotional demands of their work. Whilst online work offers the opportunity for comparatively 'safe' commercial interactions, the notion of it being 'risk'-free may be misplaced in light of unwanted interaction and wide range of online modalities. In encouraging business, most findommes in our research maintained open web profiles and messaging services, which subjected them to extensive verbal abuse and highly sexualised and unsolicited images from would-be clients and the general public.

\section{Safety, Rights, and Decriminalisation}

The research findings provide valuable insight into sex work that is safely carried out in online spaces by a large number of participants. When we reflect on what we can learn from the experiences from FDs in relation to sex work that is decriminalised, then this study provides a powerful comparison to other services which are not decriminalised. Such comparison leads us to explore the policy implications of such findings, which point to decriminalisation. Workers in any part of the economy deserve autonomy, labour, and wider human rights (such as freedom of association), and the findings also demonstrate how online findommes, in their interaction with each other, create an online community. Ergo, this study illustrates how autonomy and safety are achieved by online findommes and so adds to the growing body of literature on decriminalisation.

\section{Stigma}

The attitudes shared reflect the stigmatizing attitudes towards any form of sex (Koken, 2012; Koken et al., 2014) work as being a legitimate form of employment, even were part of lifestyle choice. In line with research literature (Ray, 2007), the felt stigma is appeared to be associated with the participant's own personal attitudes towards sex/fetish work, and hasty entry based upon financial necessity. Several responses indicated that feelings of stigma may persist long after financial domination activity has discontinued and even where activities were not disclosed or visible to others. It thereby reflecting much of the wider discourse on sex work (Brooks-Gordon, 2006) and how wider censure, rather than the work itself, may cause psychological difficulty and social exclusion (Ward \& Day, 2004). Participants were, however, able to draw upon the 'felt anonymity' (Akdenis, 2002) of DP communities to ease concern with public stigmatization and to encourage communal rationalization. The issue of stigma that underpins much of the discourse on direct sex work (Scambler, 2008; Koken, 2012) was also shown to be an important factor in financial domination. Where findommes were unable to share or disclose their interests and activities with peers, associates, and family members, then 'felt stigma' was experienced as participants indicated that they were concerned at not being able to account for their earnings or gaps in employment history filled by FD activity when seeking more traditional forms of employment. The general stigma of involvement in sex work persisted long after FD activity had ceased, and some participants feared disclosure. Many respondents also experienced enacted stigma and censure from friends and the general public. Stigma in this sense was due to association with prostitution and participants deeming to be legitimate targets for vilification. Findommes were also perceived to be 
violating accepted codes of behaviour by seeking money and gifts for humiliation and subordinating predominantly male clients. In what is a reversal of the female 'victim'/ male 'user' dynamic that pervades FTF female sex work, findommes were deemed to be exploiting male inadequacies and insecurities for personal gain. In this sense, findommes were exposed to the general stigmatisation surrounding sex work, whilst being reproached for not offering an authentic exchange for their work. By identifying work as fetish or as therapeutic in nature, some respondents legitimised their activities and managed this enacted stigmatisation.

\section{Limitations and Future Research}

These findings are by no means definitive of findomme culture and one limitation is that male dominants are underrepresented in the findings. The analysis of this subculture is confined to the activities of the findomme rather than their money slaves, and therefore, future research might investigate this area to understand the financial subjugation of clients. Future considerations for research also include the progression from financial domination into 'real-time' commercial domination activities. The possibility of fraud remains as Durkin (2007) astutely observes an important area for consideration. With easy access to DPs and the lure of 'risk-free' money, a priority for findomme research should be to determine the potential for exploitation. Although not observed, this research acknowledges however the potential for identity fraud in financial domination activity and future research should explore findomme fears and experiences in this regard.

\section{Conclusion}

This study explored financial domination via digital platforms and which reflects on the balance between increased personal independence and financial wealth, professional flexibility and learning, and significant client personal engagement and time demands. We explored whether it is challenging to maintain productivity without some compromise in the form of demands on time, emotional expenditure, and how personal boundaries are negotiated and maintained so that individual personal relationships can be managed. The occupational health and safety concerns findommes face, as well as the strategies they employ to help prevent or mitigate these concerns, are clearly shaped by structural factors like the law which impacts on stigma (Benoit et al., 2018, 2017a, b; Bungay \& Guta, 2018). It is clear from this research that, as sex workers are returning to work after the pandemic (Callender et al., 2020) and as other service sector worker turn to sex-related work, that decriminalization and the ability for findommes to ameliorate the stigma that sex work suffers, regardless of whether they identify their work as 'sex work', would enable access to and enhance support for better health, safety, and worklife balance.

Author Contribution The first author collected the data and carried out the preliminary analysis, and the first draft. The second author supervised the study, oversaw the data collection, and contributed to the data coding. The second author redrafted and rewrote the manuscript.

Data Availability Due to the nature of the research, respondents did not consent for their raw data to be shared publicly. Please contact the authors with any data queries.

\section{Declarations}

Conflict of Interest The authors declare no competing interests.

\section{References}

Abel, G. M. (2011). Different stage, different performance: The protective strategy or role play on emotional health in sex work. Social Science and Medicine, 72, 1177-1184.

Akdenis, Y. (2002). Anonymity, democracy, and cyberspace. Social Research, 69(1), 223-237.

Akers, R. L. (1985). Deviant Behavior: A social learning Approach. Wadsworth Inc.

Akers, R. L., Krohn, M. D., Lanza-Kaduce, L., \& Radosevich, M. (1997). Social learning and deviant behaviour: A specific test of a general theory. American Sociological Review, 44(4), 636-655.

ALDE. (2019) Reducing harm for vulnerable and migrant sex workers. Resolution passed at ALDE (Association of Liberal Democrats in Europe) Party Congress. Athens, Greece, 24-26 October. https://d3n8a8pro7vhmx.cloudfront.net/aldeparty/pages/1597/ attachments/original/1594142445/2019_reducing_harm_for_ migrant_and_vulnerable_sex_workers.pdf?1594142445

Angrosino, M. V. (2005). 'Recontextualizing observation: Ethnography, pedagogy, and the prospects for a progressive political agenda. In N. K. Denzin \& Y. S. Lincoln (Eds.), The Sage handbook of qualitative research (3rd ed., pp. 729-745). Sage.

Ashforth, B. E., \& Humphrey, R. H. (1993). Emotional labor in service roles: The influence of identity. Academy of Management Review, 18(1), 88-115.

Benoit, C., Jansson, M., Smith, M., \& Flagg, J. (2017a). Prostitution stigma and its effect on the working conditions, personal lives, and health of sex workers. The Journal of Sex Research, 55, 457-471.

Benoit, C., Jansson, M., Smith, M., \& Flagg, J. (2018). "Well, it should be changed for one, because it's our bodies": Sex workers' views on Canada's punitive approach towards sex work. Social Sciences, 6, 52.

Benoit, C., Jansson, M., Smith, M., Flagg, J., \& Maurice, R. (2017b). Sex work and three dimensions of self-esteem: Self-worth, authenticity and self-efficacy. Culture, Health \& Sexuality,. https://doi.org/10.1080/13691058.2017.1328075

Benoit, C., Unsworth, R., Healey, P., Smith, M., \& Jansson, M. (2021). Centering sex workers' voices in law and social policy. Sexuality Research and Social Policy. https://doi.org/10.1007/ s13178-021-00576-9 
Bernstein, E. (2007). Temporarily yours: Intimacy, authenticity, and the commerce of sex. University of Chicago Press.

Bezleh, T., Weinberg, T. S., \& Edgar, T. (2012). BDSM disclosure and stigma management: Identifying opportunities for sex education. American Journal of Sexuality Education, 7, 37-61.

Bowen, R. (2021). Work money and duality: Trading sex as a side-hustle. Policy Press

Brent et al. (2021). Open letter to the honorable Joseph R. Biden, Kamala D. Harris https://drive.google.com/file/d/ 1CDIqWyvX4WVYg2pc0LXQb1FFzjN6GHQZ/view?usp= sharing [Accessed 30 Apr 2021].

Brents, B., \& Sanders, T. (2010). Mainstreaming the sex industry: Economic inclusion and social ambivalence. Journal of Law and Society, 37(1), 40-60.

Breslow, N., Evans, L., \& Langley, J. (1985). On the prevalence and roles of females in the sadomasochistic subculture: Report on an empirical study. Archives of Sexual Behavior, 14, 303-317.

Breslow, N. (1986). Comparisons among heterosexual, bisexual, and homosexual male sadomasochists. Journal of Homosexuality, 13(1), 83-107.

Brewis, J., \& Linstead, S. (2000a). Sex, work and sex work: Eroticizing organization. Routledge.

Brewis, J., \& Linstead, S. (2000b). 'The worst thing is the screwing' (1): Consumption and the management of identity in sex work. Gender, Work and Organization, 7(2), 84-97.

Brooks-Gordon, B. (2006). The price of sex: Prostitution, policy, and society. Willan Publishing.

Brooks-Gordon, B., Mai, N., Perry, G., \& Sanders, T. (2015). Production, income, and expenditure in commercial sexual activity as a measure of GDP in the UK National Accounts. Project Report. Office for National Statistics (ONS), July. https://eprints.bbk.ac. uk/id/eprint/17962/1/17962.pdf Accessed 20 Apr 2021.

Brooks-Gordon, B., Paddick, B., Bettsworth, H., Brown, S., Cane, C., Clucas, F., Cooke, C., Cordon, S., Hobson, S., Ingham, C., Khan, M., Scott, N., \& Kyrle-Pope, W. (2017). A rational approach to harm reduction. Policy Paper 126. Spring Conference. Liberal Democrats, United Kingdom. https://d3n8a8pro7vhmx.cloudfront. net/libdems/pages/13634/attachments/original/1487768795/SW_ Policy_Paper_(Online).pdf?1487768795

Brown, A., Barker, E. D., \& Rahman, Q. (2020). Systematic scoping review of prevalence, etiological, psychological, and interpersonal factors associated with BDSM. Annual Review of Sex Research. 781-811.

Bungay, V., \& Guta, A. (2018). Strategies and challenges in preventing violence against Canadian indoor sex workers. American Journal of Public Health, 108, 393-398.

Callander, D., Meunier, É., DeVeau, R., Grov, C., Donovan, B., Minichiello, V., Singham Goodwin, A., \& Duncan, D. T. (2020). Sex workers are returning to work and require enhanced support in the face of the COVID-19: Results from a longitudinal analysis of online sex work activity and a content analysis of safer sex work guidelines. Sex Health, 17(4), 384-386. https://doi.org/10.1071/SH20128 PMID:32838836.

Campbell, R., Sanders, T., Scoular, J., Pitcher, J., \& Cunningham, S. (2019). Risking safety and rights: Online sex work, crimes and 'blended safety repertoires'. British Journal of Sociology, Sep; 70(4):1539-1560. https://doi.org/10.1111/1468-4446.12493. Epub 2018 Oct 14.PMID: 30318604.

Cascalleira, C. J., Thomson, A. \& Wignall, L. (2021). 'A certain evolution': A phenomenological study of 24/7 BDSM and negotiating consent. Psychology and Sexuality, 0:1-12.

Chapkis, W. (1997). Live sex acts: Women performing erotic labor. Routledge.

Cheng, S. J. A. (2013). A review of Danielle J. Lindemann: Dominatrix: Gender, eroticism, and control in the dungeon. Sexuality \& Culture, 17, 377-378.
Cooper, A., Delmonico, D., \& Burg, R. (2000). Cybersex users, abusers, and compulsives: New findings and implications. Sexual Addiction \& Compulsivity, 7(1-2), 5-30.

Cora Garcia, A., Standlee, A. I., Beckhoff, J., \& Cui, Y. (2009). Ethnographic approaches to the internet and computer-mediated communication. Journal of Contemporary Ethnography, 38(1), $52-84$.

De Neef, N., Coppens, V., Huys, W., \& Morrens, M. (2019). Bondagediscipline, dominance-submission sadomasochism (BDSM) From an integrative biopsychosocial perspective: A systematic review. Sexual Medicine, 7(2), 129-144.

Deshotels, T., \& Forsyth, C. J. (2006). Strategic flirting and the emotional tab of exotic dancing. Deviant Behavior, 27, 223-241.

Dunkley, C. R. \& Brotto LA. (2020). The role of consent in the context of BDSM, Sex abuse. 32(6):657-678. https://doi.org/10.1177/ 1079063219842847. Epub 2019 Apr 22.PMID: 31010393.

Durkin, K. F. (2007). Show me the money: Cybershrews and online money masochists. Deviant Behavior, 28, 355-378.

Durkin, K. F., \& Bryant, C. D. (1995). Log on to sex: Some notes on the carnal computer and erotic cyberspace as an emerging research frontier. Deviant Behavior, 16, 179-200.

Flowers, A. (1998). The fantasy factory: An insider's view of the phone sex industry. University of Pennsylvania Press.

Frost, N., Sevasti, N. M., Brooks-Gordon, B., Esin, C., Holt, A., Mehdisadeh, L., \& Shinebourne, P. (2010). Pluralism in qualitative research: The impact of different researchers and research methods on the qualitative analysis of data. Qualitative Research, 10(4), 441-460.

Garcia, J., \& Crocker, J. (2008). Reasons for disclosing depression matter: The consequences of having egosystem and ecosystem goals. Social Science and Medicine, 67(3), 453-462.

Giddens, A. (1992). The transformation of intimacy; sexuality, love and eroticism in modern societies. Polity Press.

Glaser, B., \& Strauss, A. (1967). The discovery of grounded theory. Aldine.

Grov, C., Rodríguez-Díaz, C. E., \& Jovet-Toledo, G. G. (2015). Male escorts' and male clients' behavior during their last commercial sexual encounter: Comparing and contrasting findings from two online. Archives of Sexual Behavior, 45(4), 965-973. https://doi. org/10.1007/s10508-015-0531-3

Grandey, A. (2000). Emotion regulation in the workplace: A new way to conceptualize emotional labor. Journal of Occupational Health Psychology, 5(1), 95-110.

Griffiths, M. (2016). The psychology of financial dominatrixes: A brief look at 'findommes and wallet rape', Psychology Today, 08 Dec 2016. https://www.psychologytoday.com/us/blog/in-excess/ 201612/the-psychology-financial-dominatrixes

Hakim, C. (2010). Erotic capital. European Sociological Review., 26(5), 499-518.

Heinonen, K., \& Medberg, G. (2018). Netnography as a tool for understanding customers: Implications for service research and practice. Journal of Services Marketing, 32(6), 657-679. https://doi. org/10.1108/JSM-08-2017-0294

Hoang, K. K. (2010). Economies of emotion, familiarity, fantasy, and desire: Emotional labour in Ho Chi Minh City's sex industry. Sexualities, 13, 255-272.

Hochschild, A. R. (1983). The managed heart: Commercialization of human feeling. University of California Press.

Holt, T. J., Burress, G. W., \& Bossier, A. M. (2010). Social learning and cyber deviance: Examining the importance of a full social learning model in the virtual world. Journal of Crime and Justice, 33, 31-61.

Hosie, R. (2021). What is a findom? A submissive man explains the fetish. The Independent, 24 March, https://www.independent. co.uk/life-style/love-sex/what-is-findom-fetish-b1821821.html [Accessed $20 \mathrm{Apr}$ ]. 
Inzlicht, M., Aronson, J., Good, C., \& McKay, L. (2006). A particular resiliency to threatening environments. Journal of Experimental Social Psychology, 42(3), 323-336.

Jiaou, S., \& Bungay, V. (2019). Intersections of stigma, mental health, and sex work: How Canadian men engaged in sex work navigate and resist stigma to protect their mental health. Journal of Sex Research, 56, 641-649. https://doi.org/10.1080/00224499.2018. 1459446

Jones, A. (2020). Camming: Money, power and pleasure in the sex work industry. NYU Press.

Koken, J. A. (2012). Independent female escorts' strategies for coping with sex work related stigma. Sexuality \& Culture, 3, 209-229. https://doi.org/10.1007/s12119-011-9120-3

Koken, J. A., Bimbi, D. S. \& Parsons, J. T. (2014). Positive marginality and stigma resistance among gay and bisexual male escorts. In: Aggleton, P. \& Parker, R. (Eds.). Men who sell sex: Global perspectives. Second Edition: Routledge.

Kolmes, K., Stock, W., \& Moser, C. (2006). Investigating bias in psychotherapy with BDSM clients. Journal of Homosexuality, 50(2), 301-324.

Kozinets, R. (2010). Netnography: Doing ethnographic research online. Sage.

Kozinets, R., \& Gambetti, R. (2021). Netnography: Understanding technoculture using qualitative research online. Routledge.

Langridge, D., \& Butt, T. (2005). The erotic construction of power exchange. Journal of Constructivist Psychology, 18, 65-73.

Lee, R. (1999). Doing research on sensitive topics. London. Sage.

Lindemann, D. J. (2013). Health discourse and within-group stigma in professional BDSM. Social Science and Medicine, 99, 169-175. https://doi.org/10.1016/j.socscimed.2013.08.031

Megan Smith, E. (2017). It gets very intimate for me: Discursive boundaries of pleasure and performance in sex work. Sexualities, 20(3), 344-363.

McClintock, A. (1993). Maid to order: Commercial fetishism and gender power. Social Text, 37, 87-116.

Morris, J. A., \& Feldman, D. C. (1996). The dimensions, antecedents, and consequences of emotional labor. Academy of Management Review, 21(4), 986-1010.

Morris, M. (2018). Incidental sex work: Casual and commercial encounters in queer digital space (Doctoral dissertation, Durham University) http://etheses.dur.ac.uk/13098/ [Accessed 30 May 2021].

Murthy, D. (2008). Digital ethnographies. An examination of new technologies for social research. Sociology, 42, 837-855.

O’Connell Davidson, J., \& Layder, D. (1994). Methods, sex and madness. Routledge.

O’Neill, M. (2001). Prostitution and feminism: Towards a politics of feeling. Polity Press.

Orchard, T., Salter, K., Bunch, M., \& Benoit, C. (2021). Money, agency, and self-care among cisgender and trans people in sex work. Social Sciences, 10, 6. https://doi.org/10.3390/ socsci 10010006

Palandrini, M., \& Green, L. (2000). Image management in a bondage, discipline, sadomasochist subculture: A cyberethnographic study. Cyberpsychology \& Behavior, 3(4), 631-641.

Parker, R., \& Aggleton, P. (2003). HIV and AIDS-related stigma and discrimination: A conceptual framework and implications for action. Social Science \& Medicine, 57, 13-24.

Ray, A. (2007). Sex on the open market: Sex workers harness the power of the internet. In K. Jacobs, M. Janssen, \& M. Pasquinelli (Eds) (p45-68). C'Lick Me: A netporn studies reader. Amsterdam, The Netherlands. Institute of Network Cultures.
Rich, G. J., \& Guidroz, K. (2000). Smart girls who like sex: Telephone sex workers. Sex for sale: Prostitution, pornography and the sex industry, 35-48.

Roberts, L., Smith, L., \& Pollock. C. (2004). Conducting ethical research online: Respect for individuals, identities and the ownership of words In E. A. Buchanan (ed) Virtual research ethics: Issues and controversies, pp156-73. Hershey, PA: Information Science Publishing.

Salter, A. (2011). Virtually yours: Desire and fulfilment in virtual worlds. The Journal of Popular Culture, 44(5), 1120-1137.

Sanders, T. (2004). Controllable laughter: Managing sex work through humour. Sociology, 38, 272-291.

Sanders, T. (2005a). Sex work: A risky business. Willan Publishing.

Sanders, T. (2005b). 'It's just acting: Sex workers' strategies for capitalising on sexuality'. Gender, Work and Organization, 12(4), 319-342.

Sanders, T. (2008). Male sexual scripts: Intimacy, pleasure, and sexuality in the purchase of commercial sex. Sociology, 42(3), $400-417$.

Sanders, T., Vajzovic, D., Brooks-Gordon, B., \& Mulvihill, N. (2020). Policing vulnerability in sex work and prostitution: The harm reduction compass model. Journal of Policing and Society. https://doi.org/10.1080/10439463.2020.1837825

Scambler, G., \& Paoli, F. (2008). Health work, female sex workers and HIV/Aids: Global and local dimensions of stigma and deviance as barriers to effective interventions. Social Science and Medicine, $66,1848-1862$

Scott, B. A., \& Barnes, C. M. (2011). A multilevel field investigation of emotional labor, affect, work withdrawal, and gender. Academy of Management Journal, 54(1), 116-136.

Shilo, G., \& Mor, Z. (2015). Seeking sex online: Social and sexual risk factors among adolescent and young gay and bisexual men. Sex Health, 12(3), 217-223. https://doi.org/10.1071/SH14229 PMID:25751619.

Suler, J. (2004). The online disinhibition effect. Cyberpsychology and Behavior, 7(3), 321-325.

Swallow. (2018). Digitally submissive. The Psychologist, 31, 6. May. https://thepsychologist.bps.org.uk/volume-31/may-2018/ digitally-submissive. [Accessed 20 Apr 2021].

Thomas, J., Holt, T. J., Burruss, G. W., \& Bossle, A. M. (2010). Social learning and cyber-deviance: Examining the importance of a full social learning model in the virtual world. Journal of Crime and Justice, 33(2), 31-61.

Van Wesenbeek, I. (2005). Burnout among female indoor sex workers: A review of research 1990-200. Annual Review of Research, 12, 242-290.

Vartabedian, J. (2017). Bodies and desires on the internet: An approach to trans women sex workers' websites. Sexualities, O(0), 1-20. https://doi.org/10.1177/1363346071713381

Ward, H., \& Day, S. (Eds.). (2004). Sex work mobility and health in Europe. Kegan Paul.

Weiss, B. (2018). Patterns of interaction in webcam sex work: A comparative analysis of female and male broadcasters. Deviant Behavior, 39(6), 732-746. https://doi.org/10.1080/01639625. 2017.1304803

Weiss, A. (2021). She gets paid just to humiliate her fans. New York Times, 10 April. https://www.nytimes.com/2021/04/10/style/findom-kink.html [Accessed 20 April].

Williams, D. J. (2012). Unconventional leisure and career: Insights into the work of professional dominatrices Electronic Journal of Human Sexuality, 15, March 29, www.ejhs.org

Williams, D., Prior, E. E., Alvarado, T., et al. (2016). Is bondage and discipline, dominance and submission, and sadomasochism recreational leisure? A descriptive exploratory investigation. The Journal of Sexual Medicine, 2016(13), 1091-1094. 
Wilson, A. (2005). German dominatrices' choices of working names as reflections of self-constructed social identity. Sexuality \& $\mathrm{Cul}$ ture., 9(2), 31-41.

Wood, E. A. (2000). Working in the fantasy factory: The attention hypothesis and the enacting of masculine power in strip clubs. Journal of Contemporary Ethnography, 29(1), 5-31.

Wright, S. (2006). Discrimination of SM-identified individuals. Journal of Homosexuality, 50(2), 217-231.
Zhao, S., Grasmuck, S., \& Martin, J. (2008). Identity construction on Facebook: Digital empowerment in anchored relationships. Computers in Human Behavior, 24(5), 1816-1836.

Publisher's Note Springer Nature remains neutral with regard to jurisdictional claims in published maps and institutional affiliations. 